\title{
Article \\ Effects of Growth Stage and Cd Chemical Form on Cd and Zn Accumulation in Arabidopsis halleri ssp. gemmifera
}

\author{
Hiroshi Kudo $^{1}{ }^{\mathbb{D}}$, Chihiro Inoue ${ }^{1}$ and Kazuki Sugawara ${ }^{2, *}$ \\ 1 Graduate School of Environmental Studies, Tohoku University, Miyagi 980-0845, Japan; \\ hiroshi.kudo.r4@dc.tohoku.ac.jp (H.K.); chihiro.inoue.b1@tohoku.ac.jp (C.I.) \\ 2 Faculty of Science and Technology, Seikei University, 3-3-1 Kichijoji-Kitamachi, Musahino, \\ Tokyo 180-8633, Japan \\ * Correspondence: k-sugawara@st.seikei.ac.jp
}

Citation: Kudo, H.; Inoue, C.; Sugawara, K. Effects of Growth Stage and Cd Chemical Form on $\mathrm{Cd}$ and $\mathrm{Zn}$ Accumulation in Arabidopsis halleri ssp. gemmifera. Int. J. Environ. Res. Public Health 2021, 18, 4214. https:// doi.org/10.3390/ijerph18084214

Academic Editor: Fayuan Wang

Received: 22 February 2021

Accepted: 14 April 2021

Published: 16 April 2021

Publisher's Note: MDPI stays neutral with regard to jurisdictional claims in published maps and institutional affiliations.

Copyright: (C) 2021 by the authors. Licensee MDPI, Basel, Switzerland. This article is an open access article distributed under the terms and conditions of the Creative Commons Attribution (CC BY) license (https:/ / creativecommons.org/licenses/by/ $4.0 /)$.

\begin{abstract}
Cadmium is a hazardous heavy metal and causes contamination globally. Phytoremediation can potentially become a low-cost and eco-friendly technique for mitigating Cd contamination. Arabidopsis halleri ssp. gemmifera hyper-accumulates $\mathrm{Cd}$ and $\mathrm{Zn}$, and may be used to remediate Cd-contaminated sites. However, few studies have focused on $\mathrm{Cd}$ accumulation by $A$. halleri ssp. gemmifera. Herein, we demonstrate the accumulation of Cd by A. halleri ssp. gemmifera. The biomass, $\mathrm{Cd}$, and $\mathrm{Zn}$ concentration of the plant increased in the 103 days of experimentation. Cd concentration of soil significantly decreased compared to its initial concentration $(\approx 10 \%)$. The material balance of Cd uptake by plant and Cd decrement from soil ranged from $63.3 \%$ to $83.7 \%$ in each growth stage. Analysis indicated that the water-eluted and exchangeable forms of $\mathrm{Cd}$ were stable during the experiment. However, $\mathrm{Cd}$ concentration extracted with $0.1 \mathrm{M} \mathrm{HCl}$ decreased ( $25 \%$ of initial), and this fraction was not bioavailable. The study exhibits the mass balance of $\mathrm{Cd}$ between plant uptake and decrement from the soil and the changes in the chemical form of Cd during stages of $A$. halleri ssp. gemmifera cultivation.
\end{abstract}

Keywords: Arabidopsis halleri ssp. gemmifera; cadmium; chemical form; heavy metal accumulation; phytoremediation

\section{Introduction}

Cadmium $(\mathrm{Cd})$ is present in trace amounts in zinc $(\mathrm{Zn})$, lead $(\mathrm{Pb})$, and copper $(\mathrm{Cu})$ ores. During mining and beneficiation of these ores, $\mathrm{Cd}$ is discharged into rivers and accumulates in downstream soil through seepage water from mine shafts, drainage, and waste rock deposits [1]. Cd pollution has become a concern in China and other emerging countries as $\mathrm{Cd}$ moves through the soil and easily enters the food chain via plant uptake (vegetables, root crops, cereals, and grains) [2,3]. Surveying a wide area covering $70 \%$ of China from 2005 to 2013, 8 inorganic pollutants (As, Cd, Co, Cr, Cu, Hg, Mg, and $\mathrm{Ni}$ ) and three organic pollutants (BHC, DDT, PAH) were discovered in every square $\mathrm{km}$ of the surface soil (0-20 cm thick). Soil Cd concentrations were exceeded most frequently, with $7.0 \%$ of samples exceeding the standard established by the Chinese Ministry of Environmental Protection [4]. In addition, Tong et al. [5] reported an increased risk of Cd exposure from Chinese urban soils during 2003-2019. Furthermore, wheat, which is consumed by over half of the global population, is known to absorb $\mathrm{Cd}$ from its roots and accumulate it in grains. This has increased the concerns regarding potential health hazards [6].

As $\mathrm{Cd}$ accumulates in rice, the regions with high rice consumption, such as Japan and other Asian countries, are concerned about the effects of $\mathrm{Cd}$ on human health. Although $\mathrm{Cd}$ in nature does not cause acute poisoning, chronic poisoning may occur due to longterm $\mathrm{Cd}$ exposure at relatively low levels. A serious example of this is Itai-Itai disease, which occurred in the Jinzu River basin in Toyama Prefecture [7]. Itai-Itai disease occurred downstream of Kamioka mine which was the largest $\mathrm{Zn}$ mine in the world in the 1960s. 
A Cd contaminated site was remediated by excavation, which took 33 years in the case of Japan [8]. The cost was approximately 100 million USD for $7.63 \mathrm{~km}^{2}$. Generally, for remediation of such contaminated sites, excavation is believed to be a swift and certain remediation technique. However, it is time-consuming, and moving the contaminated soil is expensive. Hence, a low-cost novel technology with a low environmental load is required.

Phytoremediation is an environmental remediation technology that utilizes the biological functions of plants, and the cost and environmental impact are lower than other remediation technologies such as excavation and soil washing [9]. Heavy metals are accumulated in the aerial part of the plant via vital activity, and the plant is then harvested along with the accumulated heavy metals. Plants which can accumulate very high concentration of heavy metals are called hyperaccumulator (>100 mg/kg of Cd). Arabidopsis halleri ssp. gemmifera is a plant native to East Asia [10] that hyper-accumulates Cd and Zn. In hydroponic cultivation, it accumulated maximum Cd and Zn of $5641 \mathrm{mg} / \mathrm{kg}$ dry weight (DW) and 26,400 $\mathrm{mg} / \mathrm{kg}$ DW, respectively [11,12].

Heavy metals exist in various chemical forms in the soil; water-soluble form is easily eluted by water as ions and is available for plant uptake (i.e., bioavailable). The exchangeable form is bound to layers of clay or adsorbed on the soil surface, and this form can be exchanged for another cation. Therefore, it is considered potentially bioavailable. Carbonate form is bound to carbonates, and oxide form is bound to oxide compounds of Fe and Mn [13]. These heavy metals are eluted in natural conditions, such as weathering, erosion of plant roots, etc. Water-soluble and exchangeable forms are easily eluted by plant and microbial activity (organic acid from roots and microbial activity in rhizosphere) [14]. Potential bioavailability is strongly controlled by the chemical forms of the metals [15].

In the earlier studies with $A$. halleri ssp. gemmifera, the total Cd concentration of soil decreased from $5.0 \mathrm{mg} / \mathrm{kg}$ to $1.0 \mathrm{mg} / \mathrm{kg}$ [16]. Additionally, Cd extracted by $0.1 \mathrm{M} \mathrm{HCl}$ (oxide form of $\mathrm{Cd}$ ) decreased from $3.5 \mathrm{mg} / \mathrm{kg}$ to $0.6 \mathrm{mg} / \mathrm{kg}$ in the pot experiments [16]. In another experiment, $\mathrm{Cd}$ concentration (extracted by $0.1 \mathrm{M} \mathrm{HCl}$ ) decreased from $3.45 \mathrm{mg} / \mathrm{kg}$ to $0.81 \mathrm{mg} / \mathrm{kg}$ in the soil after four seasons of extraction by A. halleri ssp. gemmifera [17]. However, reports do not show a clear material balance between $\mathrm{Cd}$ removal from soil and $\mathrm{Cd}$ uptake by the plant. Additionally, little is known about behavior of Cd uptake by $A$. halleri ssp. gemmifera from soil where only a fraction of metal is bioavailable [18]. Hence, it is necessary to evaluate $\mathrm{Cd}$ accumulation by $A$. halleri ssp. gemmifera, its material balance between soil and plants and $\mathrm{Cd}$ chemical form.

Generally, plants change their nutrient requirements [19] and transcriptional regulation [20] according to growth stage. Although $\mathrm{Cd}$ is considered to be non-essential nutrient for A. halleri ssp. gemmifera, the chemical behavior of $\mathrm{Cd}$ resembles that of $\mathrm{Zn}$ which is essential nutrient, and it has been reported that $\mathrm{Cd}$ and $\mathrm{Zn}$ pass through a similar transportation pathway [21]. Therefore, behavior of $\mathrm{Cd}$ uptake by plant might be changed according to growth stage. Understanding of detailed behavior of hyperaccumulating plants absorbing heavy metal from early germination to maturity may contribute to improvement of phytoextraction.

The present study investigated $\mathrm{Cd}$ accumulation by A. halleri ssp. gemmifera and the consequent mass balance between soil and plants in a pot experiment. Additionally, the relationship between the chemical form of $\mathrm{Cd}$ and its accumulation by plant uptake was explored.

\section{Materials and Methods}

\subsection{Plant and Soil Preparation and Pot Experiment}

Soil containing $\mathrm{Cd}$ and $\mathrm{Zn}$ was collected from a farmland located downstream of the Hosokura Mine, Tome city, Miyagi Prefecture. The initial concentrations of $\mathrm{Cd}$ and $\mathrm{Zn}$ in the soil were $4.94 \mathrm{mg} / \mathrm{kg}$ and $601.3 \mathrm{mg} / \mathrm{kg}$, respectively. A. halleri ssp. gemmifera were grown from the seed, and plants with heights of 3 to $5 \mathrm{~cm}$ were used for the experiment. The soil was filled in pots of two sizes (small: diameter $11 \mathrm{~cm}$, depth $10 \mathrm{~cm}$; large: diameter 
$21 \mathrm{~cm}$, depth $20 \mathrm{~cm}$ ) up to $80 \%$ of the total volume and A. halleri ssp. gemmifera was planted in the center of each pot. The dry weight of the soil in the small pots was $0.61 \pm 0.03 \mathrm{~kg}$, and that in the large pots was $3.06 \pm 0.19 \mathrm{~kg}$. To ensure that plant growth was not limited by the previous study [22], the amount of soil was kept below $1 \mathrm{~g} / \mathrm{L}$ plant biomass weight/soil volume. The experiment was conducted from 10 September to 22 December 2014 (103 days). Plants were cultivated under natural conditions until 15 November (66th day), where the maximum temperature in each day was above $15^{\circ} \mathrm{C}$. Thereafter, the plants were moved to a greenhouse maintained at a temperature over $15^{\circ} \mathrm{C}$ to ensure stable growing conditions. Plants were harvested at early growth stage (35th and 75th day) from small pots, and at late growth stage (94th and 103rd day) from large pots in triplicates. Sampling was conducted when major changes in plant appearance occurred, with emergence of new leaf after 35 days, death of leaves that were present at planting after 75 days, further leaf emergence after 94 days, and upward leaf elongation after 103 days. During rains, pots were covered with a clear plastic sheet to prevent $\mathrm{Cd}$ draining from contaminated soil.

\subsection{Plants and Soil Analysis Subsection}

Plant materials were harvested in a manner to avoid separation of shoots and roots, and then washed with Milli-Q water. Thereafter, plants were divided into shoots and roots and were measured for fresh weight before oven-drying at $60^{\circ} \mathrm{C}$ for $48 \mathrm{~h}$, following which the dry-weight was measured. Plant samples weighing $0.01 \mathrm{~g}$ were placed in a glass test tube to which $2 \mathrm{~mL}$ of $\mathrm{HNO}_{3}$ was added and heated at $130{ }^{\circ} \mathrm{C}$ by a heat block (Aluminum Block Bath ALB-121, SCINICS) for $2 \mathrm{~h}$. The samples were then digested and diluted by Milli-Q water so that the concentration of the target element was approximately $100 \mu \mathrm{g} / \mathrm{L}$. The obtained sample was analyzed via inductively coupled plasma mass spectrometry (ICP-MS, ELAN 9000, Perkin-Elmer), just as in Sugawara et al. [23].

After harvesting, soil samples were sieved through a pore diameter of $2 \mathrm{~mm}$ and homogenized. Different fractions of the soil sample were extracted by Milli-Q water, $\left(\mathrm{NH}_{4}\right)_{2} \mathrm{SO}_{4}$, and $\mathrm{HCl}$ [24]. The water-soluble fraction was extracted by Milli-Q water and considered to be bioavailable. The exchangeable fraction was extracted by $\left(\mathrm{NH}_{4}\right)_{2} \mathrm{SO}_{4}$ solution and was also bioavailable because it is assumed that the exudation of the plant dissolves this fraction. $\mathrm{HCl}$-soluble fraction was extracted by $\mathrm{HCl}$ solution. The details of extraction are shown in Table 1.

Table 1. Method of extraction.

\begin{tabular}{ccccccc}
\hline Method of Extraction & Solvent & Soil Weight & $\begin{array}{c}\text { Solvent } \\
\text { Volume }\end{array}$ & $\begin{array}{c}\text { Solvent } \\
\text { Concentration }\end{array}$ & Shaking Speed & Shaking Time \\
\hline Water extraction * & Milli-Q water & $3 \mathrm{~g}$ & $30 \mathrm{~mL}$ & - & $200 \mathrm{rpm}$ & $6 \mathrm{~h}$ \\
\hline Exchangeable extraction & $\left(\mathrm{NH}_{4}\right)_{2} \mathrm{SO}_{4}$ & $1 \mathrm{~g}$ & $20 \mathrm{~mL}$ & $0.05 \mathrm{~mol} / \mathrm{L}$ & $200 \mathrm{rpm}$ & $4 \mathrm{~h}$ \\
\hline $\mathrm{HCl}-$ soluble extraction & & $\mathrm{HCl}$ & $5 \mathrm{~g}$ & $25 \mathrm{~mL}$ & $1.0 \mathrm{~mol} / \mathrm{L}$ & $100 \mathrm{rpm}$ \\
\hline
\end{tabular}

* Water extraction and $\mathrm{HCl}$ extraction were based on the elution test and measuring content test, respectively, established by Ministry of the Environment in Japan.

Extracted samples were centrifuged at $3300 \mathrm{rpm}(=1500 \times \mathrm{g})$ for $20 \mathrm{~min}$ and the supernatant liquid was diluted by Milli-Q water for ICP-MS analysis. For finding total concentration of $\mathrm{Cd}$ and $\mathrm{Zn}$, soil samples were oven-dried at $60{ }^{\circ} \mathrm{C}$ until the weights stabilized. The dried soil sample was ground (VIBRATING SAMPLE MILL Tl-100, CMT). The powdered samples were made into pellet using a press machine (Atlas Manual Hydraulic Press 15T, Specac Ltd., Orpington, UK) and then analyzed via X-ray fluorescence spectrometer (XRF, Epsilon 5, PANalytical), as also described in Sugawara et al. [23]. 


\section{Results}

\subsection{Biomass Yield and Heavy Metals Concentration of Arabidopsis halleri ssp. gemmifera}

The plant biomass of A. halleri ssp. gemmifera is shown in Figure 1. The plant biomass increased well through the experimental period. Specifically, biomass of shoots rapidly increased after the early growth stage (from 75th day to 103rd day). On the 103rd day, biomass of shoots and roots of A. halleri ssp. gemmifera reached $0.62 \pm 0.17 \mathrm{~g} / \mathrm{plant}$ $\mathrm{DW}$ and $0.19 \pm 0.06 \mathrm{~g} / \mathrm{plant} \mathrm{DW}$, respectively. Although the final height of the plant is approximately $30 \mathrm{~cm}$, the stem did not grow vertically in this phase. Therefore, growing old leaves and geminating young leaves allowed an increase in plant biomass (Figure 2).

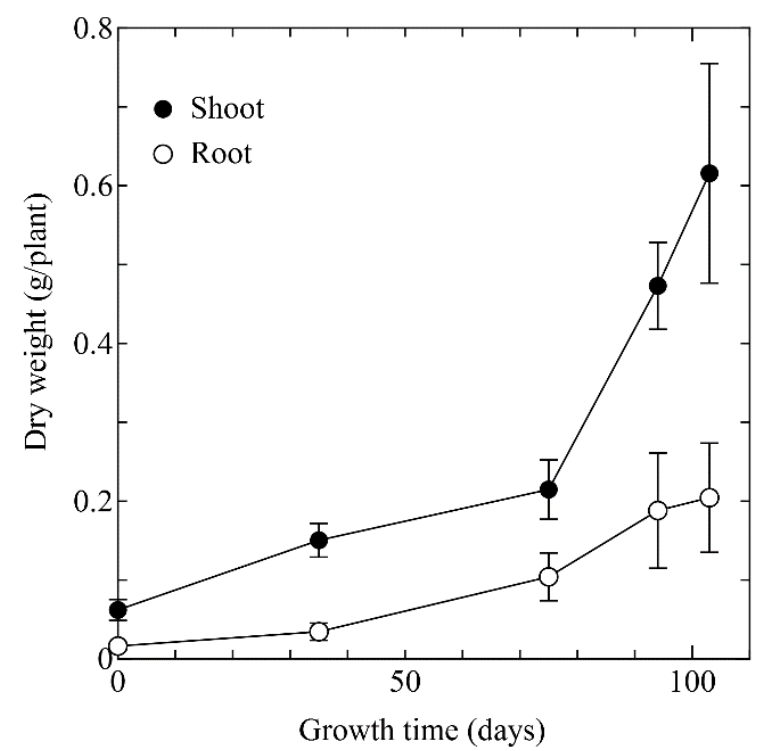

Figure 1. Changes in biomass of shoots and roots of A. halleri ssp. gemmifera. Black circle: Shoot; white circle: Root. Error bars represent standard deviation of three independent samples.
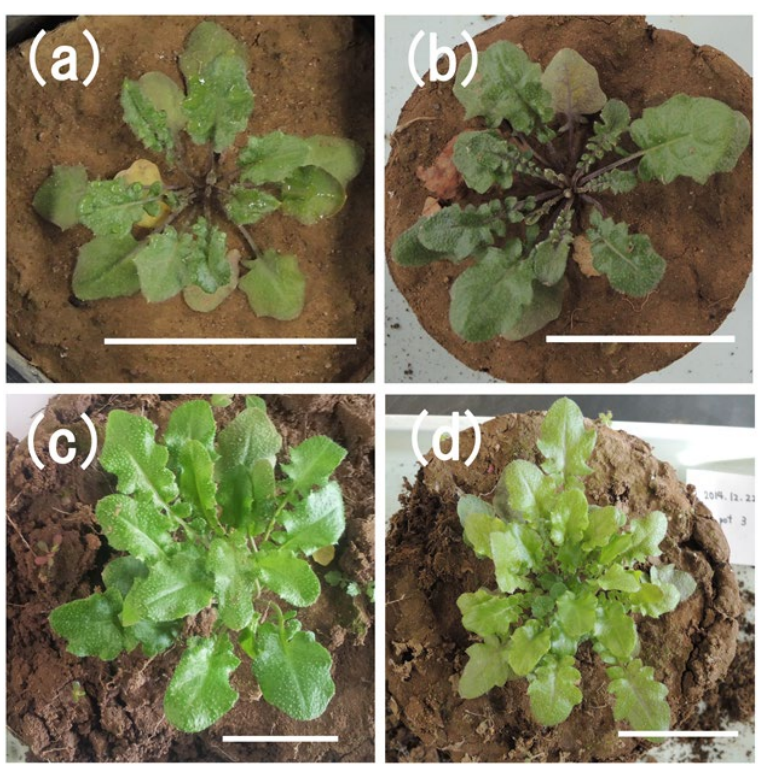

Figure 2. Photo of A. halleri ssp. gemmifera at (a) 35th day, (b) 75th day, (c) 94th day, and (d) 103rd day. Each scale bar is $5 \mathrm{~cm}$.

At the late growth stage, roots were spread across the entire pot area. Hence, it was assumed that plants could absorb heavy metals throughout the soil. The result of $\mathrm{Cd}$ and $\mathrm{Zn}$ concentration in shoots and roots of A. halleri ssp. gemmifera is shown in Figure 3. Total 
heavy metals concentration in shoots rapidly increased after the early growth stage and was the same as the biomass of the shoots. Maximum heavy metal concentrations in shoots on the $103 \mathrm{rd}$ day were $1.89 \times 10^{3} \mathrm{mg} / \mathrm{kg}$ and $2.64 \times 10^{4} \mathrm{mg} / \mathrm{kg}$ for Cd and $\mathrm{Zn}$, respectively. This result was comparable to that of a previous study performed for 9 months in field conditions using the same $\mathrm{Cd}$ and $\mathrm{Zn}$ contaminated soil [25]. In this study, well-maintained and suitable growth conditions (regular water supply and well-controlled temperature) were provided, and hence, it was assumed that the plants constantly absorbed heavy metals. Meanwhile, heavy metal concentrations in roots increased moderately. Maximum heavy metal concentrations in roots were $3.00 \times 10^{2} \mathrm{mg} / \mathrm{kg}$ and $3.20 \times 10^{3} \mathrm{mg} / \mathrm{kg}$ for Cd and $\mathrm{Zn}$, respectively, on the 103rd day.
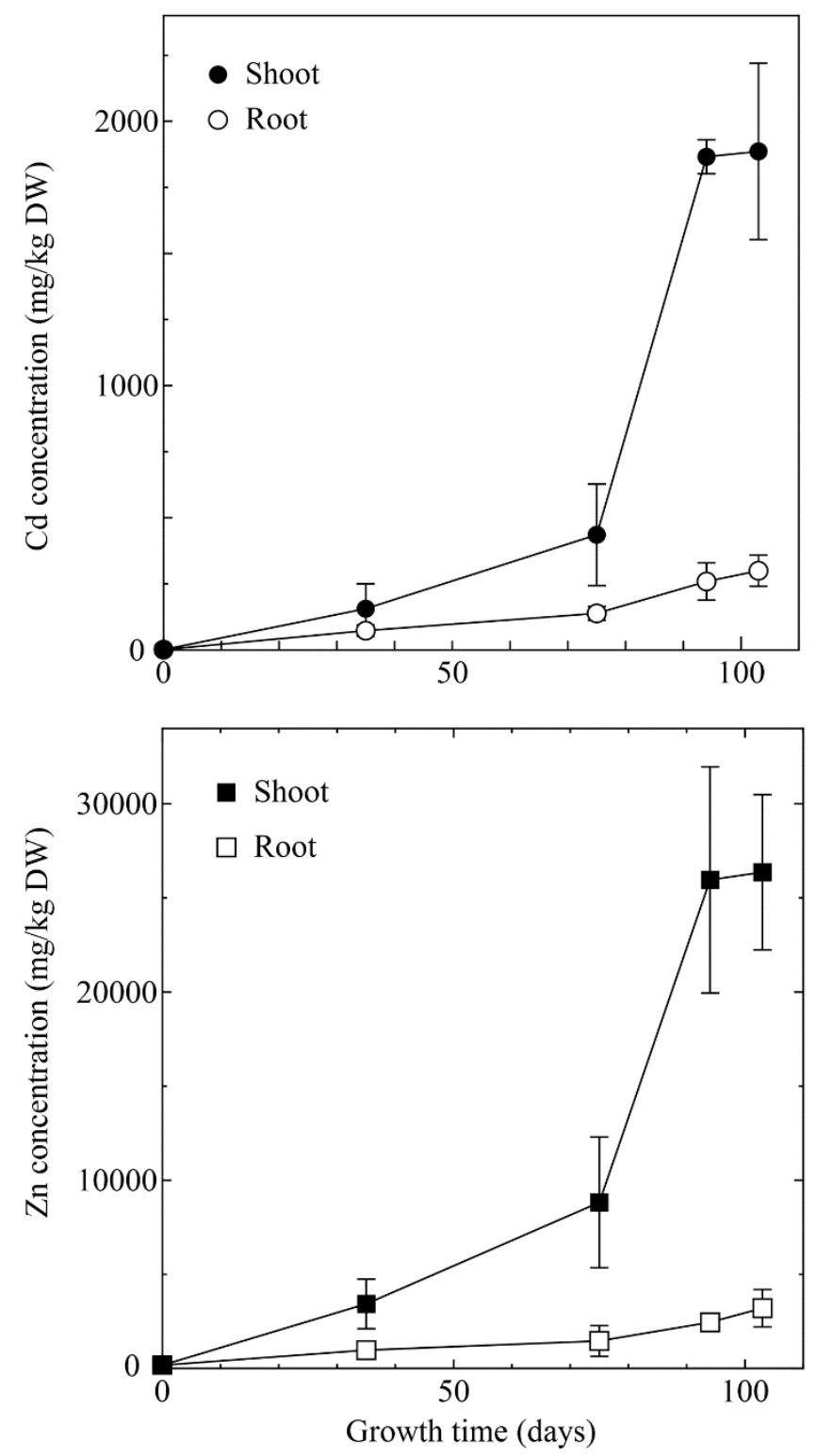

Figure 3. Changes in $\mathrm{Cd}$ and $\mathrm{Zn}$ concentration in shoots and roots of A. halleri ssp. gemmifera. Black circle and square: Shoot; white circle and square: Root. Error bars represent the standard deviation of three independent samples.

\section{2. $\mathrm{Cd}$ and $\mathrm{Zn}$ Concentration of Contaminated Soil}

The results of $\mathrm{Cd}$ and $\mathrm{Zn}$ concentrations of contaminated soil are shown in Figure 4. Total Cd concentration gradually decreased from $4.94 \mathrm{mg} / \mathrm{kg}$ to $4.45 \pm 0.17 \mathrm{mg} / \mathrm{kg}$. During the experiment, the total $\mathrm{Cd}$ concentration reduced by approximately $10 \%$. The results 
show that the total $\mathrm{Cd}$ concentration in soil significantly decreased in only 3 months by A. halleri ssp. gemmifera cultivation. Contrastingly, the total $\mathrm{Zn}$ concentration in soil did not decrease in the experimental period. Although A. halleri ssp. gemmifera was considered to absorb $\mathrm{Zn}$ in the soil (Figure 3), the amount of Zn was large, and hence, $\mathrm{Zn}$ uptake by the plant did not reflect the decrease in $\mathrm{Zn}$ in soil. Variation in total $\mathrm{Zn}$ concentration in the soil during the experiment was observed, which could be attributed to insufficient soil homogenization when adding soil to the pots.
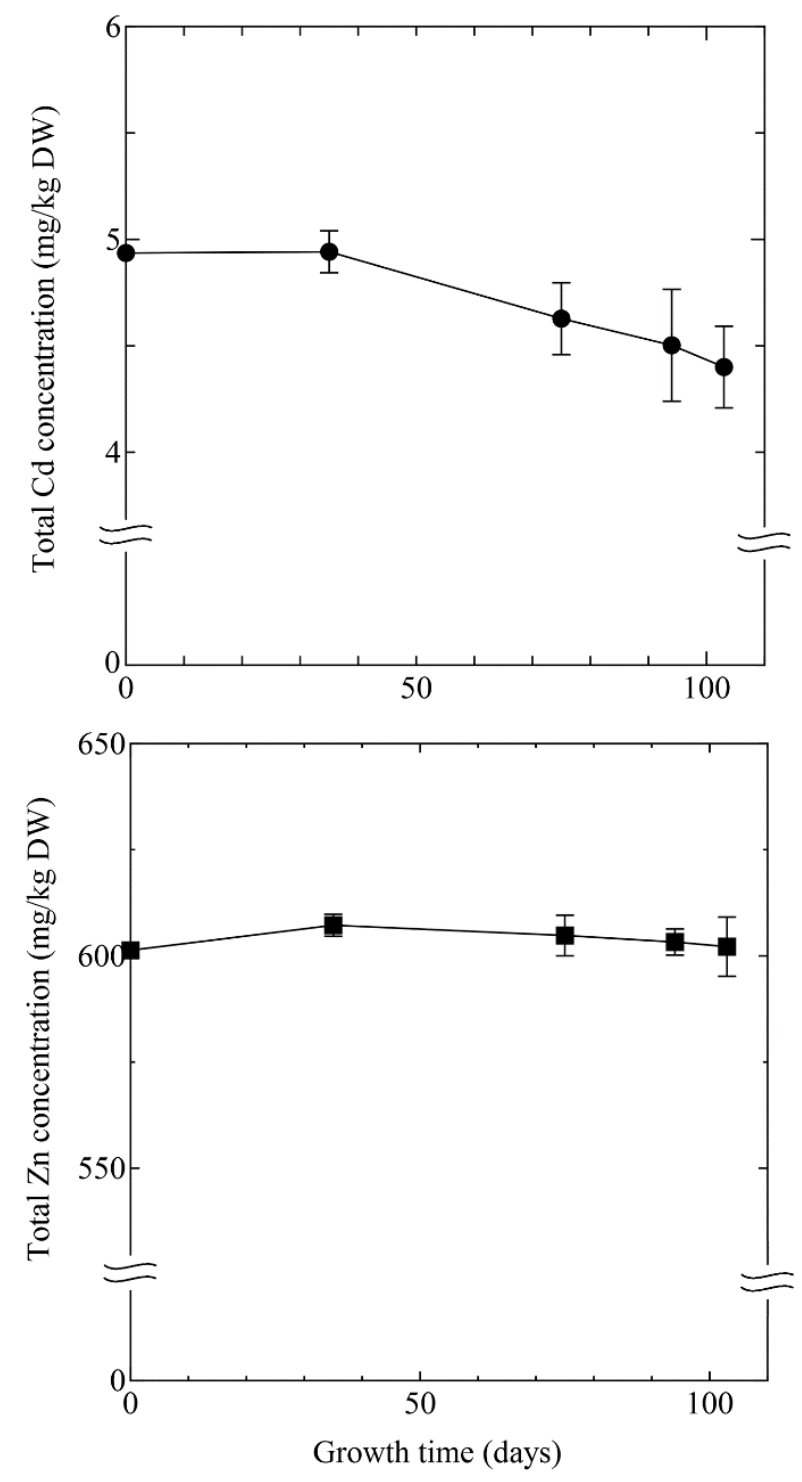

Figure 4. Changes in $\mathrm{Cd}$ and $\mathrm{Zn}$ concentration in soil. Black circle: Cd concentration; black square: Zn concentration. Error bars represent the standard deviation of three independent samples.

\subsection{Material Balance between Soil and Plant}

The above results show a significant accumulation of $\mathrm{Cd}$ by the plants and its consequent reduction from the soil. The ratio of removal $\left(\mathrm{R}_{\mathrm{p} / \mathrm{s}}\right)$, which represents the mass balance of $\mathrm{Cd}$ between soil and plant, was calculated from the results as shown in Sections 3.1 and 3.2 to reveal the mass balance relationship. Additionally, the translocation factor (TF), bioconcentration factor (BCF), and accumulation factor (AF) were calculated to verify phytoextraction efficiency [26]. TF, BCF, and $\mathrm{AF}$ are the indicators of translocation from roots to shoots, accumulation from soil to shoots, and accumulation from soil to the entire plant, respectively. The value of $R_{p / s}, T F, B C F$, and $A F$ are shown in Table 2. 
Table 2. Material balance between soil and plant.

\begin{tabular}{cccccccccc}
\hline Growth Time (Days) & \multicolumn{2}{c}{ 35 Days } & \multicolumn{2}{c}{ 75 Days } & \multicolumn{2}{c}{ 94 Days } & \multicolumn{1}{c}{ 103 Days } \\
\hline Cd decrement in soil (mg) & -0.01 & \pm 0.08 & 0.18 & \pm 0.11 & 1.17 & \pm 0.33 & 1.47 & \pm 0.39 \\
\hline $\begin{array}{c}\text { Cd increment } \\
\text { in plant (mg) }\end{array}$ & 0.03 & \pm 0.08 & 0.11 & \pm 0.06 & 0.93 & \pm 0.08 & 1.20 & \pm 0.27 \\
\hline Cd Rp/s (\%) & 17.6 & \pm 58.5 & 63.3 & \pm 16.7 & 83.7 & \pm 24.3 & 83.2 & \pm 10.1 \\
\hline Cd TF & 2.03 & \pm 0.75 & 3.04 & \pm 0.92 & 7.49 & \pm 1.56 & 6.32 & \pm 0.28 \\
\hline Cd BCF & 31.2 & \pm 18.1 & 95.2 & \pm 44.1 & 410 & \pm 19.1 & 424 & \pm 80.3 \\
\hline Cd AF & 28.0 & \pm 15.3 & 72.7 & \pm 29.9 & 311 & \pm 19.9 & 336 & \pm 59.6 \\
\hline Zn TF & 3.54 & \pm 1.01 & 6.98 & \pm 4.17 & 10.9 & \pm 3.87 & 8.65 & \pm 2.14 \\
\hline Zn BCF & 5.65 & \pm 2.17 & 14.6 & \pm 5.84 & 43.1 & \pm 10.2 & 43.8 & \pm 7.36 \\
\hline Zn AF & 4.88 & \pm 1.78 & 10.5 & \pm 3.89 & 32.5 & \pm 9.77 & 34.3 & \pm 4.59 \\
\hline
\end{tabular}

Each condition has three replicates. $\mathrm{Rp} / \mathrm{s}$ of $\mathrm{Zn}$ was not calculated because the concentration of $\mathrm{Zn}$ in soil barely decreased. $\mathrm{TF}=\mathrm{Cd}$ or $\mathrm{Zn}$ concentration in shoots $/ \mathrm{Cd}$ or $\mathrm{Zn}$ concentration in roots. $\mathrm{BCF}=\mathrm{Cd}$ or $\mathrm{Zn}$ concentration in shoots $/ \mathrm{Cd}$ or $\mathrm{Zn}$ concentration in soil. $\mathrm{AF}=\mathrm{Cd}$ or $\mathrm{Zn}$ concentration in the entire plant/Cd or $\mathrm{Zn}$ concentration in soil.

After the 75th day, the mass balance $\left(\mathrm{Cd} \mathrm{R}_{\mathrm{p} / \mathrm{s}}\right)$ ranged from $63.3 \pm 16.7 \%$ to $83.7 \pm 24.3 \%$. This indicated that the most of $\mathrm{Cd}$ in soil was absorbed by A. halleri ssp. gemmifera, rather than drained from the pot. This study highlights the relationship between $\mathrm{Cd}$ in plants and in soil, which has not been reported previously.

$\mathrm{Cd}$ TF values ranged from $2.03 \pm 0.75$ to $7.49 \pm 1.56$. Meanwhile, $\mathrm{BCF}$ and $\mathrm{AF}$ values rapidly increased from the 75th to the 94th day, and ranged from $31.2 \pm 18.1$ to $424 \pm 80.3$ and $28.0 \pm 15.3$ to $336 \pm 59.6$, respectively. The earlier study of A. halleri ssp. gemmifera where AF value of $\mathrm{Cd}$ was between 52 and 200 (average $=88$ ) [16]. The AF value in this experiment was higher than that of the earlier study. The Zn TF values ranged from $3.54 \pm 1.01$ to $10.9 \pm 3.87$, and were higher than Cd TF values for each sampling time. The BCF and AF values ranged from $5.65 \pm 2.17$ to $43.8 \pm 7.36$ and $4.88 \pm 1.78$ to $34.3 \pm 4.59$, respectively.

Additionally, it appeared that the translocation speed of heavy metals from roots to shoots was different between the early growth stage and late growth stage in this study (Figure 3). The TF results show that Cd from the root was not transported to the shoot immediately in the early growth stage. Most recently, Qian et al. have observed that $\mathrm{Zn}$ is transported from the roots to the aerial parts at a faster rate than $\mathrm{Cd}$, in whole plant of living $A$. halleri ssp. gemmifera using radioactive $\mathrm{Zn}$ and $\mathrm{Cd}$ (personal communication). Therefore, the same trend was confirmed in the present study.

Extraction experiments were conducted to verify the Cd fraction absorbed mainly by the plant. $\mathrm{Cd}$ concentrations of water-soluble fraction, exchangeable fraction, and $\mathrm{HCl}$-soluble fraction in the soil are shown in Figure 5. Cd concentration of water-soluble fraction ranged from $0.020 \mathrm{mg} / \mathrm{kg}$ to $0.030 \mathrm{mg} / \mathrm{kg}$ in the experimental period, and this fraction was presumed as a bioavailable fraction. Contrastingly, the exchangeable fraction, which was also presumed as a bioavailable fraction, tended to decline. The final concentration was $0.20 \pm 0.04 \mathrm{mg} / \mathrm{kg}$, which was half the initial concentration $(0.46 \mathrm{mg} / \mathrm{kg})$. The concentration of the $\mathrm{HCl}$-soluble fraction is not bioavailable. However, the concentration slightly decreased from $2.5 \mathrm{mg} / \mathrm{kg}$ to $2.0 \pm 0.15 \mathrm{mg} / \mathrm{kg}$. The concentration of $\mathrm{Cd}$ in the $\mathrm{HCl}$-soluble fraction increased from 94 to 103 days. However, as approximately half of the total concentration of $\mathrm{Cd}$ in soil was not leached by $\mathrm{HCl}$, the change to the leachable form possibly occurred because of a change in chemical equilibrium due to absorption of soluble Cd by plants. 


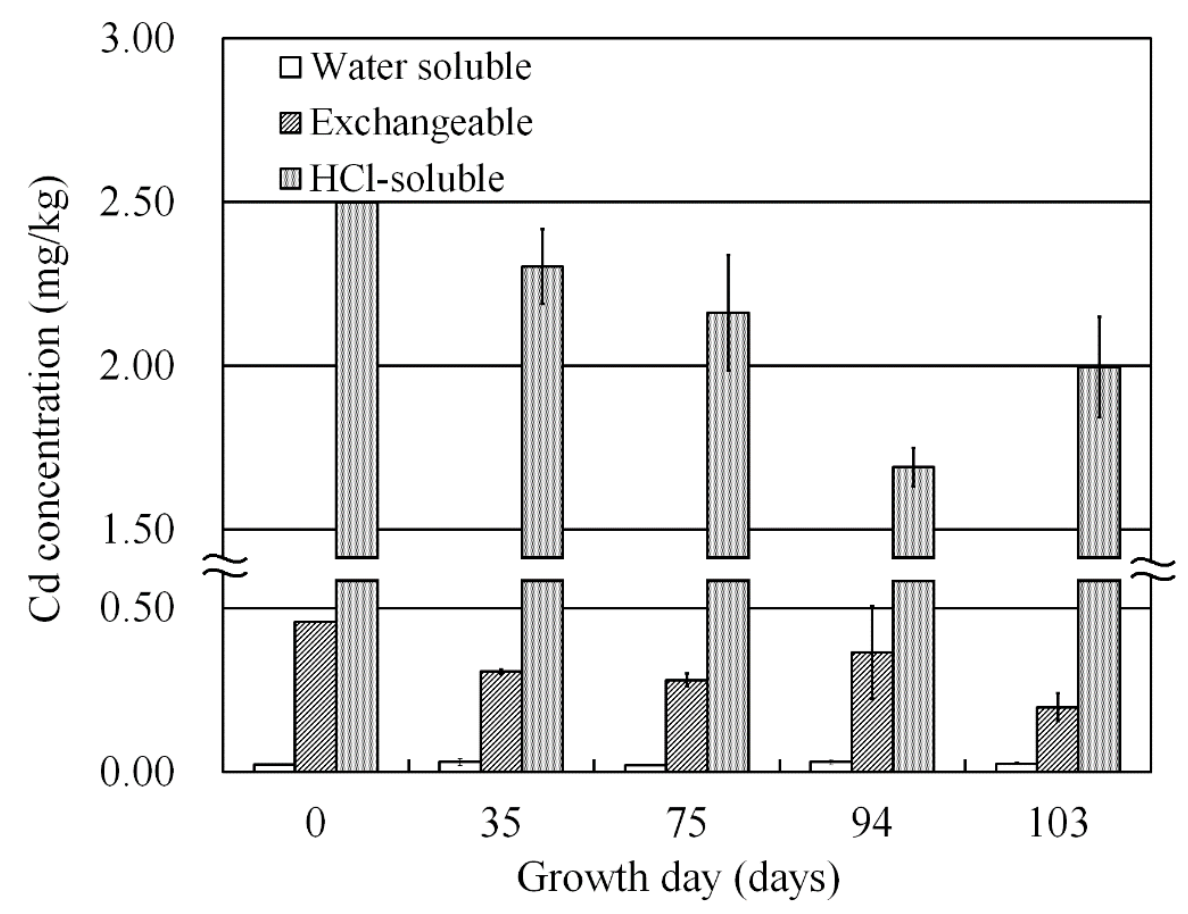

Figure 5. Cd concentration of water-soluble, exchangeable, and $\mathrm{HCl}$ - soluble fraction in contaminated soil. White bar: water-soluble fraction; dark gray bar: exchangeable fraction; light gray bar: $\mathrm{HCl}-$ soluble fraction. Error bars represent standard deviation of three independent samples.

\section{Discussion}

Fukuda et al. [21] suggested that $\mathrm{Cd}$ and $\mathrm{Zn}$ followed a similar pathway because the correlation of the distribution of $\mathrm{Cd}$ and $\mathrm{Zn}$ between trichomes and leaf was positive on XRF intensities experiment. Bert et al. [27] showed evidence of a generic correlation between $\mathrm{Cd}$ and $\mathrm{Zn}$ accumulations in the aerial parts of A. halleri. Generally, Cd contaminated soil contains $\mathrm{Zn}$, as $\mathrm{Cd}$ is derived from zinc ore. A. halleri ssp. gemmifera is also a hyperaccumulator of $\mathrm{Zn}$. Therefore, phytoextraction of $\mathrm{Cd}$ should be performed without interference by $\mathrm{Zn}$. If the $\mathrm{Cd}$ pathway is the same as $\mathrm{Zn}$, then $\mathrm{Cd}$ uptake by the plant could be obstructed by $\mathrm{Zn}$ uptake. However, $A$. halleri ssp. gemmifera absorbed $\mathrm{Cd}$ adequately (maximum concentration in shoot: $1.89 \times 10^{3} \mathrm{Cd} \mathrm{mg} / \mathrm{kg}$ ) without $\mathrm{Zn}$ obstruction in this experiment. Hence, A. halleri ssp. gemmifera can be applied to Cd phytoremediation of soil containing $\mathrm{Zn}$. Furthermore, Cd uptake pathway may be different from that of the $\mathrm{Zn}$ uptake. $\mathrm{Zn}$ concentration in soil was 100 times that of $\mathrm{Cd}$, and the concentration in shoots was approximately 10 times that of $\mathrm{Cd}$. Although heavy metal concentration in soil was drastically different, the difference in concentration in shoots was smaller than in soil. This result indicated different pathways for $\mathrm{Cd}$ and $\mathrm{Zn}$ uptake. In cases of iron (Fe) deficiency, the root of Arabidopsis induces the expression of the divalent cation transporter such as IRT1, which is essential for the uptake of Fe from the soil and responsible for the uptake of heavy metals such as Cd [28].

In a previous pot experiment conducted for 3-4 months of plant cultivation using $5.4 \mathrm{mg} / \mathrm{kg} \mathrm{Cd}$ contaminated soil and $3000 \mathrm{~cm}^{3}$ pot, the maximum $\mathrm{Cd}$ concentration in the plant was $753 \mathrm{mg} / \mathrm{kg}$ at the flowering phase [29]. The result obtained in this study was 2.5 times higher than in the previous report. It may represent the difference in chemical and physical properties of soil, such as cation exchangeable capacity (CEC), amount of organic matter, and content of silt influencing Cd mobility. Therefore, it is assumed that the soil properties of this experiment may affect the suitability for $\mathrm{Cd}$ uptake by $A$. halleri ssp. gemmifera. Contrastingly, soil properties affect plant biomass owing to the presence of nutrients and water retention potential. As the phytoextraction potential is determined by the production of biomass [30], soil properties should be considered in future studies. 
The concentrations of exchangeable fraction and $\mathrm{HCl}$-soluble fraction decreased through the experimental period of the study. Hence, to confirm that the exchangeable fraction is the dominant form absorbed by plants, the difference in the decrement in concentrations between three fractions, namely total $\mathrm{Cd}$, exchangeable, and $\mathrm{HCl}$-soluble, is shown in Figure 6.

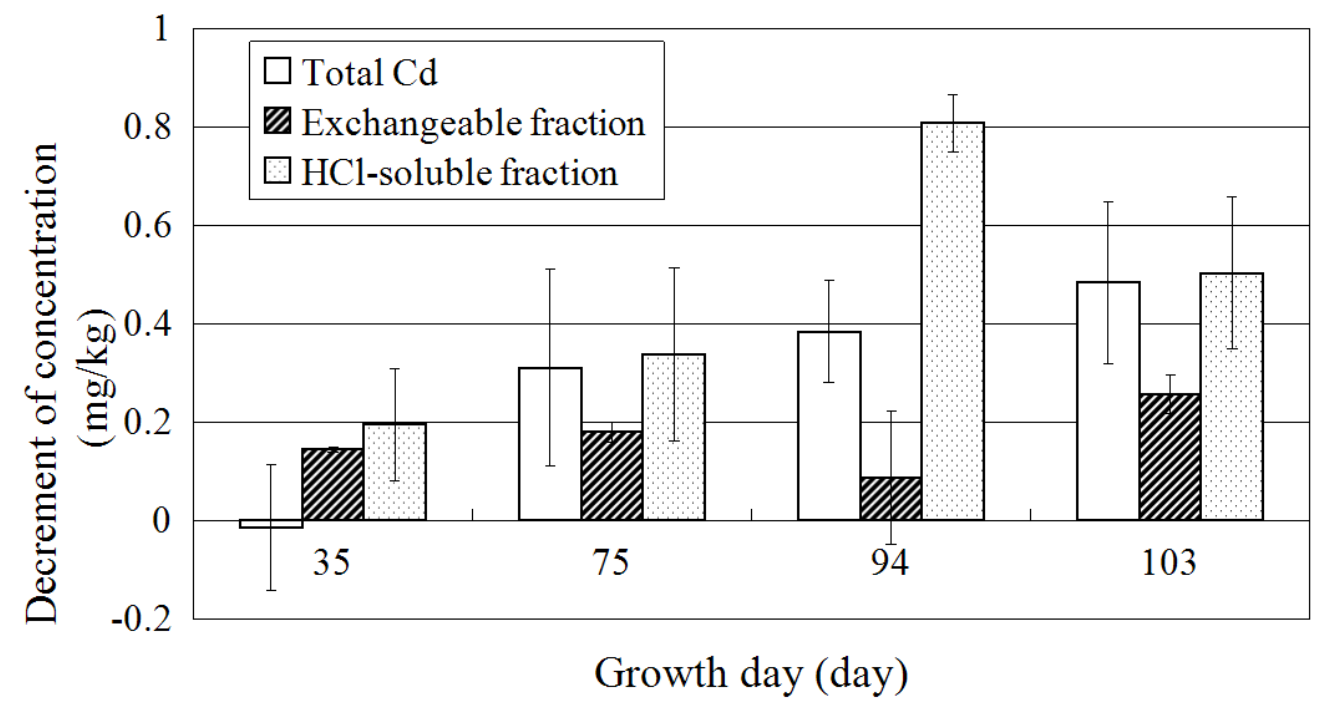

Figure 6. Comparison with decrement of total $\mathrm{Cd}$, exchangeable fraction, and HCl-soluble fraction. White bar: Total Cd; shaded bar: exchangeable fraction; dotted bar: HCl-soluble fraction. Error bars represent standard deviation of three independent samples.

Although it is assumed that plants absorb the exchangeable fraction of $\mathrm{Cd}$, decrement in the exchangeable fraction was less than total $\mathrm{Cd}$ after 75 days. In contrast, the decrement in the $\mathrm{HCl}$-soluble fraction of Cd was the same as the total Cd on the 75th and 103rd days. Nevertheless, the $\mathrm{HCl}$ fraction was not bioavailable. Kubota et al. [16] reported that $\mathrm{HCl}-$ soluble fraction (extracted by $0.1 \mathrm{M} \mathrm{HCl}$ ) in soil decreased for 10 months of A. halleri ssp. gemmifera cultivation. Degryse et al. [31] suggested that insoluble Cd was slowly released over a long time when exchangeable $\mathrm{Cd}$ was depleted. Results of this study indicate that $\mathrm{HCl}$-soluble fraction supplied $\mathrm{Cd}$ to an exchangeable fraction when plants absorbed exchangeable $\mathrm{Cd}$. Meanwhile, the chemical form of heavy metals in soil was affected by other factors, such as weathering, activity of microbes, and effect of root exudates. Gradd [32] reported that micro-organisms could mobilize metals through the microbial processes, such as autotrophic and heterotrophic leaching and chelation by microbial metabolites (organic acids) and siderophores. Furthermore, water-soluble and exchangeable fractions of heavy metals increased by the influence of air-drying [33].

The extraction method may give useful information on heavy metals, although the chemical form of $\mathrm{Cd}$ in soil is affected by several factors. Some previous reports attempted to upregulate the change in heavy metal chemical forms from stable to bioavailable form [34]. This study clarified for the first time the dynamics of $\mathrm{Cd}$ form shifting through plant accumulation. Demonstrating the form of $\mathrm{Cd}$ absorbed by the plant and elucidating mechanisms of plant uptake of $\mathrm{Cd}$ can improve phytoremediation, and hence investigations with other methods are necessary.

Generally, plants acquire nutrients including metal form soil by releasing root exudates [35] and microorganisms in rhizosphere [36]. In the present study, plant biomass was rapidly increased from the early growth stage to the late growth stage. Cd accumulation in shoot was also increased along with increasing biomass, although A. halleri ssp. gemmifera reached to maximum $\mathrm{Cd}$ concentration in shoot in a short period ( 3 weeks) regardless of biomass in the previous study using hydroponic culture [11]. This result indicates that the amount of root exudate is increased along with increasing biomass, and 
it leads to increasing $\mathrm{Cd}$ bioavailability in soil. It has been reported that rice root and shoot biomass were positively correlated with root carbon exudation [37]. Additionally, plant growth stage might affect composition of root exudates. Gransee and Wittenmayer [38] reported that the relative amount of sugars in root exudates decreased during plant development. Accordingly, exudates from plant roots might be a remarkable topic for future research. Hoffland [39] reported that rapeseed released citric and malic acids from its root in phosphorus-deficient conditions. Acidification of the rhizosphere enhances the mobilization of rock of phosphate. White lupin [40], maize [41], and soybean [42] also release organic acid to acidify the rhizosphere. Releasing exudates is a common strategy by plants to acquire nutrients. Additionally, wheat exudates enhanced mobility of heavy metals $(\mathrm{Zn}$, $\mathrm{Cu}$, and $\mathrm{Cd}$ ) in Fe deficient condition [39]. Root exudates of Nicotiana tabacum L., which is one of the Cd hyperaccumulators, enhances the mobility of $\mathrm{Cd}$ in soil [43]. As organic acid can supply both protons and metal complexing anions, it is assumed that organic acid is heavily involved with $\mathrm{Cd}$ mobilization. Contrarily, it was reported that exudates of Thlaspi caerulescens known for $\mathrm{Cd}$ and $\mathrm{Zn}$ hyperaccumulation did not enhance $\mathrm{Cd}$ mobility [44]. Thus, the functions of root exudates are different for each plant species and have not been elucidated yet. As it is not clear whether A. halleri ssp. gemmifera enhances Cd mobility in soil, the relationship between plant uptake and form of $\mathrm{Cd}$ must be demonstrated to understand rhizospheric interaction. To summarize, the study revealed $\mathrm{Cd}$ accumulation by $A$. halleri ssp. gemmifera and its mass balance between Cd chemical form in soil and subsequent shifting in form by plant uptake in pot experiments. This report may contribute to the improvement in the phytoremediation technique and understanding the relationship between heavy metals and plants in the environment. For future research, the relationship between root exudates and $\mathrm{Cd}$ fraction in the soil must be investigated.

\section{Conclusions}

In the present study, we investigated the effect of growth stage and chemical form of heavy metal to the accumulation of $\mathrm{Cd}$ and $\mathrm{Zn}$ by A. halleri ssp. gemmifera. The biomass, $\mathrm{Cd}$, and $\mathrm{Zn}$ concentration of the plant increased in the 103 days of our experiment. $\mathrm{Cd}$ concentration of soil significantly decreased compared to its initial $(\approx 10 \%)$. Mass balance of Cd uptake by plant and Cd decrement from soil ranged from $63.3 \%$ to $83.7 \%$ in each growth stage. Analysis indicated that the water-eluted and exchangeable forms of $\mathrm{Cd}$ were stable during the experiment. However, $\mathrm{Cd}$ concentration extracted with $0.1 \mathrm{M}$ $\mathrm{HCl}$ decreased (by $25 \%$ of the initial value), and this fraction was not bioavailable. The study showed the mass balance of $\mathrm{Cd}$ between plant uptake and decrement from the soil and the changes in the chemical form of $\mathrm{Cd}$ during different stages of $A$. halleri ssp. gemmifera cultivation. However, influence of A. halleri ssp. gemmifera on the Cd chemical form change are not investigated adequately. Therefore, in future study, the effect of root exudates of each growth stage on soil needs to be investigated. This study may contribute molecular biological analysis and other methods to facilitate the understanding of the mechanism of hyperaccumulation and tolerance to heavy metals, which is not exhibited by ordinary plants.

Author Contributions: Conceptualization, C.I.; investigation, writing—original draft, H.K.; writingreview and editing, funding acquisition, K.S. All authors have read and agreed to the published version of the manuscript.

Funding: This research was funded by Grant-in-Aid for Young Scientists (B): 17K12834; Grant-in-Aid for JSPS Fellows: 266414 and Grant-in-Aid for Scientific Research (A): 19 H01158.

Institutional Review Board Statement: Not applicable.

Informed Consent Statement: Not applicable.

Data Availability Statement: The data presented in this study are available on request from the corresponding author upon reasonable request. 
Acknowledgments: We would like to thank Nobuyuki Kitajima at Fujita Co. for providing seedlings of A. halleri ssp. gemmifera.

Conflicts of Interest: The authors declare no conflict of interest.

\section{References}

1. Satarug, S.; Haswell-Elkins, M.R.; Moore, M.R. Safe levels of cadmium intake to prevent renal toxicity in human subjects. Br. J. Nutr. 2000, 84, 791-802. [CrossRef]

2. Smolders, E. Cadmium uptake by plants. Int. J. Occup. Med. Environ. Health 2001, 14, 177-183.

3. Klaassen, C.D.; Casarett, L.J.; Doull, J. Casarett and Doull's Toxicology: The Basic Science of Poisons; McGraw-Hill: New York, NY, USA, 2013.

4. Zhao, F.-J.; Ma, Y.; Zhu, Y.-G.; Tang, Z.; McGrath, S.P. Soil contamination in China: Current status and mitigation strategies. Environ. Sci. Technol. 2015, 49, 750-759. [CrossRef] [PubMed]

5. Tong, S.; Li, H.; Wang, L.; Tudi, M.; Yang, L. Concentration, spatial distribution, contamination degree and human health risk assessment of heavy metals in urban soils across China between 2003 and 2019-A systematic review. Int. J. Environ. Res. Public Health 2020, 17, 3099. [CrossRef]

6. Abedi, T.; Mojiri, A. Cadmium uptake by wheat (Triticum aestivum L.): An overview. Plants 2020, 9, 500. [CrossRef] [PubMed]

7. Nishijo, M.; Nakagawa, H.; Suwazono, Y.; Nogawa, K.; Kido, T. Causes of death in patients with Itai-itai disease suffering from severe chronic cadmium poisoning: A nested case-control analysis of a follow-up study in Japan. BMJ Open 2017, 7, e015694 [CrossRef]

8. The Ministry of Agriculture, Forestry and Fisheries in Japan, Hokuriku Regional Agricultural Administration Office. Restoration of Cd Contaminated Agricultural Soil around Jinzu River in Toyama Prefecture, Japan. 2013. Available online: http:/ /www.maff. go.jp/hokuriku/news/print/50nen_ayumi/pdf/13_17-18_50ayumi.pdf (accessed on 10 February 2021).

9. Lee, J.H. An overview of phytoremediation as a potentially promising technology for environmental pollution control. Biotechnol. Bioprocess Eng. 2013, 18, 431-439. [CrossRef]

10. Kubota, H.; Takenaka, C. Arabis gemmifera is a hyperaccumulator of Cd and Zn. Int. J. Phytoremediat. 2003, 5, 197-201. [CrossRef]

11. Kashem, A.; Singh, B.R.; Kubota, H.; Nagashima, R.S.; Kitajima, N.; Kondo, T.; Kawai, S. Assessing the potential of Arabidopsis halleri ssp. gemmifera as a new cadmium hyperaccumulator grown in hydroponics. Can. J. Plant Sci. 2007, 87, 499-502. [CrossRef]

12. Kashem, A.; Singh, B.R.; Kubota, H.; Sugawara, R.; Kitajima, N.; Kondo, T.; Kawai, S. Zinc tolerance and uptake by Arabidopsis halleri ssp. gemmifera grown in nutrient solution. Environ. Sci. Pollut. Res. 2010, 17, 1174-1176. [CrossRef]

13. Tessier, A.; Campbell, P.G.C.; Bisson, M. Sequential extraction procedure for the speciation of particulate trace metals. Anal. Chem. 1979, 51, 844-851. [CrossRef]

14. Hu, L.; McBride, M.B.; Cheng, H.; Wu, J.; Shi, J.; Xu, J.; Wu, L. Root-induced changes to cadmium speciation in the rhizosphere of two rice (Oryza sativa L.) genotypes. Environ. Res. 2011, 111, 356-361. [CrossRef] [PubMed]

15. Xian, X. Effect of chemical forms of cadmium, zinc, and lead in polluted soils on their uptake by cabbage plants. Plant Soil 1989, 113, 257-264. [CrossRef]

16. Kubota, H.; Sugawara, R.; Kitajima, N.; Yajima, S.; Tani, S. Cadmium phytoremediation by Arabidopsis halleri ssp. gemmifera. J. Soil Sci. Plant Nutr. 2010, 81, 118-124. (In Japanese)

17. Tani, S.; Kameyama, K. Phytoextraction with Arabidopsis halleri ssp. gemmifera to remediate Cd-contaminated soils. Global Environ. Res. 2009, 15, 55-62. (In Japanese)

18. Lasat, M.M. Phytoextraction of toxic metals. J. Environ. Qual. 2002, 31, 109-120.

19. Maeda, Y.; Konishi, M.; Kiba, T.; Sakuraba, Y.; Sawaki, N.; Kurai, T.; Ueda, Y.; Sakakibara, H.; Yanagisawa, S. A NIGT1-centered transcriptional cascade regulates nitrate signalling and incorporates phosphorus starvation signals in Arabidopsis. Nat. Commun. 2018, 9, 1376. [CrossRef] [PubMed]

20. Nazoa, P.; Vidmar, J.J.; Tranbarger, T.J.; Mouline, K.; Damiani, I.; Tillard, P.; Zhuo, D.; Glass, A.D.; Touraine, B. Regulation of the nitrate transporter gene AtNRT2.1 in Arabidopsis thaliana: Responses to nitrate, amino acids and developmental stage. Plant Mol. Biol. 2003, 52, 689-703. [CrossRef] [PubMed]

21. Fukuda, N.; Hokura, A.; Kitajima, N.; Terada, Y.; Saito, H.; Abe, T.; Nakai, I. Mico X-xray fluorescence imaging and micro X-ray adsorption spectroscopy of cadmium hyper-accumulating plant, Arabidopsis halleri ssp. gemmifera, using high-energy synchrotron radiation. J. Anal. At. Spectrom. 2008, 23, 1068-1075. [CrossRef]

22. Poorter, H.; Hler, J.B.; van Dusschoten, D.; Climent, J.; Postma, J.A. Pot size matters: A meta-analysis of the effects of rooting volume on plant growth. Funct. Plant Biol. 2012, 39, 839-850. [CrossRef] [PubMed]

23. Sugawara, K.; Kobayashi, A.; Endo, G.; Hatayama, M.; Inoue, C. Evaluation of the effectiveness and salt stress of Pteris vittata in the remediation of arsenic contamination caused by tsunami sediments. J. Environ. Sci. Health Part A 2014, 49, 1631-1638. [CrossRef]

24. Sugawara, K.; Wen, X.; Haung, Y.; Miyauchi, K.; Endo, G.; Kitajima, N.; Inoue, C. Evaluation ability to accumulate Cd and Zn of Arabidpsis halleri ssp. gemmifera in field and hydroponic study. In Proceedings of the 11th International Phytotechnologies Conference, Heraklion, Crete, Greece, 30 September-3 October 2014.

25. Zhang, Z.; Wen, X.; Huang, Y.; Inoue, C.; Liang, Y. Higher accumulation capacity of cadmium than zinc by Arabidopsis halleri ssp. germmifera in the field using different sowing strategies. Plant Soil 2017, 418, 165-176. [CrossRef] 
26. Ali, H.; Khan, E.; Sajad, M.A. Phytoremediation of heavy metals-Concepts and applications. Chemosphere 2013, 91, 869-881. [CrossRef] [PubMed]

27. Bert, V.; Meerts, P.; Saumitou-Laprade, P.; Salis, P.; Gruber, W.; Verbruggen, N. Genetic basis of Cd tolerance and hyperaccumulation in Arabidopsis halleri. Plant Soil 2003, 249, 9-18. [CrossRef]

28. Vert, G.; Grotz, N.; Dédaldéchamp, F.; Gaymard, F.; Guerinot, M.L.; Briat, J.-F.; Curie, C. IRT1, an Arabidopsis transporter essential for iron uptake from the soil and for plant growth. Plant Cell 2002, 14, 1223-1233. [CrossRef] [PubMed]

29. Kameyama, K.; Tani, S.; Sugawara, R.; Ishikawa, Y. Applicability of phytoextraction with Arabidopsis halleri ssp. gemmifera to remediate Cd-contaminated Andisols. Trans. Jpn. Soc. Irrig. 2009, 259, 99-106. (In Jpananese)

30. Tlustoš, P.; Száková, J.; Hrubý, J.; Hartman, I.; Najmanová, J.; Nedělník, J.; Pavlíková, D.; Batysta, M. Removal of As, Cd, Pb, and Zn from contaminated soil by high biomass producing plants. Plant Soil Environ. 2018, 52, 413-423. [CrossRef]

31. Degryse, F.; Buekers, J.; Smolders, E. Radio-labile cadmium and zinc in soils as affected by pH and source of contamination. Eur. J. Soil Sci. 2004, 55, 113-122. [CrossRef]

32. Gradd, G.M. Microbial influence on metal mobility and application for bioremediation. Geoderma 2004, 122, 109-119.

33. Makino, T.; Hasegawa, S.; Sakurai, Y.; Ohno, S.; Utagawa, H.; Maejima, Y.; Momohara, K. Influence of soil-drying under field conditions on exchangeable manganese, cobalt, and copper contents. Soil Sci. Plant Nutr. 2000, 46, 581-590. [CrossRef]

34. McGrath, S.P.; Zhao, F.; Lombi, E. Plant and rhizosphere processes involved in phytoremediation of metal-contaminated soils. Plant Soil 2001, 232, 207-214. [CrossRef]

35. Chen, Y.-T.; Wang, Y.; Yeh, K.-C. Role of root exudates in metal acquisition and tolerance. Curr. Opin. Plant Biol. 2017, 39, 66-72. [CrossRef] [PubMed]

36. Pii, Y.; Mimmo, T.; Tomasi, N.; Terzano, R.; Cesco, S.; Crecchio, C. Microbial interactions in the rhizosphere: Beneficial influences of plant growth-promoting rhizobacteria on nutrient acquisition process. A review. Biol. Fertil. Soils 2015, 51, 403-415. [CrossRef]

37. Aulakh, M.S.; Wassmann, R.; Bueno, C.; Kreuzwieser, J.; Rennenberg, H. Characterization of root exudates at different growth stages of ten rice (Oryza sativa L.) cultivars. Plant Biol. 2001, 3, 139-148. [CrossRef]

38. Gransee, A.; Wittenmayer, L. Qualitative and quantitative analysis of water-soluble root exudates in relation to plant species and development. J. Plant Nutr. Soil Sci. 2000, 163, 381-385. [CrossRef]

39. Hoffland, E. Quantitative evaluation of the role of organic acid exudation in the mobilization of rock phosphate by rape. Plant Soil 1992, 140, 279-289. [CrossRef]

40. Dinkelaker, B.; Romheld, V.; Marschner, H. Citric acid excretion and precipitation of calcium citrate in the rhizosphere of white lupin (Lupinus albus L.). Plant Cell Environ. 1989, 12, 285-292. [CrossRef]

41. Gaume, A.; Machler, F.; De Leon, C.; Narro, L.; Frossard, E. Low-P tolerance by maize (Zea mays L.) genotypes: Significance of root growth, and organic acids and acid phosphatase root exudation. Plant Soil 2001, 228, 253-264. [CrossRef]

42. Dong, D.; Peng, X.; Yan, X. Organic acid exudation induced by phosphorus deficiency and/or aluminium toxicity in two contrasting soybean genotypes. Physiol. Plant. 2004, 122, 190-199. [CrossRef]

43. Mench, M.; Martin, E. Mobilization of cadmium and other metals from two soils by root exudates of Zea mays L., Nicotiana tabacum L. and Nicotiana rustica L. Plant Soil 1991, 132, 187-196. [CrossRef]

44. Zhao, F.J.; Hamon, R.E.; McLaughlin, M.J. Root exudates of the hyperaccumulator Thlaspi caerulescens do not enhance metal mobilization. New Phytol. 2001, 151, 613-620. [CrossRef] 